\title{
Apocrine Neoplasm
}

National Cancer Institute

\section{Source}

National Cancer Institute. Apocrine Neoplasm. NCI Thesaurus. Code C6798.

A benign or malignant sweat gland neoplasm with apocrine differentiation.

Representative examples include apocrine adenoma, ceruminous adenocarcinoma, and apocrine breast carcinoma. 